\title{
Resistencia a la meticilina y producción de biopelícula en aislamientos clínicos de Staphylococcus aureus y Staphylococcus coagulasa negativa en México
}

Ayerim García1, Carlos Martínez ${ }^{1,2}$, Rosa Isela Juárez³, René Téllez ${ }^{3}$, Marco Antonio Paredes ${ }^{4}$, María del Rocío Herrera ${ }^{1}$, Silvia Giono ${ }^{1}$

${ }^{1}$ Laboratorio de Bacteriología Médica, Departamento de Microbiología, Escuela Nacional de Ciencias Biológicas, Instituto Politécnico Nacional, Ciudad de México, México

2 Servicio de Bioquímica, Instituto Nacional de Rehabilitación "Luis Guillermo Ibarra Ibarra", Ciudad de México, México

${ }^{3}$ Laboratorio Central de Patología Clínica, Instituto Nacional de Rehabilitación "Luis Guillermo Ibarra Ibarra", Ciudad de México, México

${ }^{4}$ Laboratorio de Neurobiología, Instituto Nacional de Rehabilitación "Luis Guillermo Ibarra Ibarra", Ciudad de México, México

Introducción. Las infecciones por Staphylococcus aureus y Staphylococcus coagulasa negativa multirresistentes a los antibióticos y asociadas con la atención en salud tienen un gran impacto epidemiológico por su alta morbimortalidad; además, se han relacionado con la formación de biopelículas, lo cual también se asocia con la resistencia a los antimicrobianos.

Objetivo. Determinar la resistencia a la meticilina y cuantificar la producción de biopelículas para establecer su posible relación con los aislamientos clínicos de $S$. aureus y Staphylococcus coagulasa negativa.

Materiales y métodos. Se estudiaron 11 cepas de $S$. aureus y 12 de Staphylococcus coagulasa negativa. La resistencia a la meticilina se determinó con discos de cefoxitina tomando como valores de referencia los estándares del Clinical Laboratory Standards Institute (CLSI) de 2018. La producción de biopelícula se cuantificó con cristal violeta. Los genes mecA e ica $A D B C$ se identificaron mediante reacción en cadena de la polimerasa (PCR), y se hizo un análisis bivariado con la prueba de ji al cuadrado y el coeficiente $V$ de Cramér, utilizando el programa SPSS ${ }^{\mathrm{TM}}$, versión 20.0.

Resultados. Nueve cepas de $S$. aureus fueron resistentes a la meticilina (SARM) y dos fueron sensibles. Ocho cepas de Staphylococcus coagulasa negativa fueron resistentes y cuatro fueron sensibles. El genotipo mecA se encontró en ocho de las nueve cepas de $S$. aureus y en seis de las ocho de Staphylococcus coagulasa negativa resistentes a meticilina. Todas las cepas formaron biopelícula. Diez cepas de $S$. aureus y 11 de Staphylococcus coagulasa negativa presentaron el genotipo icaADCB. No se encontró asociación entre la resistencia a meticilina y la formación de biopelícula.

Conclusiones. La cefoxitina es suficiente para determinar el fenotipo resistente a meticilina y se asoció con el genotipo mecA. Las cepas resistentes a la meticilina y poseedoras del gen mecA pueden presentar un mecanismo de resistencia alterno. Los dos grupos de cepas formadoras de biopelícula se relacionaron con la presencia del operón ica $A D C B$. La formación de biopelícula y la resistencia a la meticilina se expresaron como características independientes en los dos grupos de cepas.

Palabras clave: Staphylococcus aureus resistente a meticilina; biopelículas; México.

Methicillin resistance and biofilm production in clinical isolates of Staphylococcus aureus and coagulase-negative Staphylococcus in México

Introduction: Infections associated with health care caused by $S$. aureus and coagulasenegative Staphylococci multi-resistant to antibiotics cause a high epidemiological impact due to their high morbidity and mortality. Biofilm formation, which has been associated with antimicrobial resistance, can also occur.

Objectives: To determine methicillin resistance and to quantify the biofilm production to establish if there is a relationship in clinical isolates of $S$. aureus and coagulase-negative Staphylococci. Material and methods: A total of 11 strains of $S$. aureus and 12 of coagulase-negative Staphylococci were studied. Methicillin resistance was determined with cefoxitin discs and the Clinical Laboratory Standards Institute (CSLI), 2018 reference values. Biofilm production was quantified by the crystal violet method. The mecA and icaADBC genes were identified by PCR. A bivariate analysis was performed with chi-square $\left(\mathrm{c}^{2}\right)$ and Cramér's $\mathrm{V}$ statistical tests, using SPSSTM, version 20.0 software.

Results: Nine $S$. aureus strains were methicillin-resistant and two were sensitive. Eight coagulase-negative Staphylococci strains were resistant and four were sensitive. The mecA 
genotype was found in eight of the nine $S$. aureus resistant strains and six of eight resistant coagulase-negative Staphylococci. All strains formed biofilms. Ten strains of $S$. aureus and 11 of coagulase-negative Staphylococci presented the icaADCB genotype. No association was found between methicillin-resistance and biofilm formation.

Conclusions: Cefoxitin is enough to define the resistance phenotype and is associated with the mecA genotype. All strains formed biofilms and were related to the presence of the ica $A D C B$ operon. Biofilm formation and methicillin resistance were independent features in both groups of strains.

Keywords: Methicillin-resistant Staphylococcus aureus; biofilms; México.

Las infecciones asociadas con la atención en salud representan un problema de salud pública debido a su alta morbilidad y mortalidad. Los agentes patógenos que las causan en México pertenecen al grupo de bacterias Gram positivas Staphylococcus aureus y Staphylococcus coagulasa negativa, al de las bacterias Gram negativas Acinetobacter baumannii y Pseudomonas aeruginosa, y al de especies pertenecientes a Enterobacteriaceae $(1,2)$.

Staphylococcus spp. son cocos Gram positivos de 0,5 a 1,5 $\mu \mathrm{m}$ de diámetro que se agrupan en racimos, son inmóviles, anaerobios facultativos, fermentadores de glucosa, positivos para catalasa y negativos para oxidasa, con un contenido de $\mathrm{G}+\mathrm{C}$ de 30 a $39 \%$, y son oportunistas (3). Staphylococcus aureus es la especie más virulenta; se la considera una bacteria extracelular que induce alteraciones en los tejidos y produce lesiones localizadas con supuración y cicatrización, y es responsable de varias infecciones en el humano (4).

Los factores que incrementan la probabilidad de adquirir dichas infecciones incluyen la hospitalización durante periodos prolongados, los procedimientos preoperatorios, la utilización de catéteres o prótesis y la permanencia en lugares de alto riesgo (unidades de cuidados intensivos, entre otros), pero los principales factores de riesgo son la virulencia, el potencial para formar abscesos y la multirresistencia a los antibióticos (5).

La Red Hospitalaria de Vigilancia Epidemiológica de México ha reportado que la mortalidad en pacientes infectados con S. aureus varía de 5 a $70 \%$. La información proveniente de los hospitales generales, pediátricos, universitarios y de especialidades señala que $S$. aureus ocupó el tercer lugar en morbilidad y el cuarto lugar en mortalidad en el periodo de 1997 a 2003 (5).

La resistencia del género Staphylococcus a los $\beta$-lactámicos, como las penicilinas, las cefalosporinas y los carbapenémicos, es un problema de salud pública (6). La resistencia a la penicilina en $S$. aureus surgió a finales de la década de 1950 y obligó al desarrollo de nuevos antimicrobianos. Así aparecieron las primeras cefalosporinas estables frente a las penicilinasas y las penicilinas semisintéticas, entre ellas la meticilina. Un año después de su introducción, se aisló en Europa la primera cepa de $S$. aureus resistente a la meticilina (SARM) y, en 1963, se reportó el primer brote hospitalario; desde entonces se han notificado en todo el mundo (4).

Los mecanismos de resistencia de $S$. aureus a los $\beta$-lactámicos son la producción de enzimas $\beta$-lactamasas, la presencia de proteínas ligadas a la penicilina (Penicillin Binding Protein, PBP) modificadas (conocida como resistencia intrínseca a la meticilina) y los fenómenos de tolerancia. Las penicilinas resistentes a penicilinasas (oxacilina, meticilina, cloxacilina) poseen una estructura molecular que las protege frente a la acción de las $\beta$-lactamasas. El mecanismo de resistencia de $S$. aureus a la meticilina se 
basa en la síntesis de una nueva PBP (PBP2a o PBP2'), la cual exhibe poca afinidad por la meticilina y otros $\beta$-lactámicos, bloquea la llegada del antibiótico a su sitio blanco y produce, así, un patrón de resistencia (7).

El elemento genético cromosómico responsable de la resistencia es el gen $m e c A$, cuya expresión depende de dos genes, el $m e c R 1$, que regula la transcripción, y el mecl, que codifica la proteína represora. El antibiótico $\beta$-lactámico induce un proceso catalítico en la membrana bacteriana, y el gen $m e c A$ se transcribe y se sintetiza en la proteína de membrana PBP2a $(8,9)$.

Otras modalidades de resistencia en las que no se evidencia la presencia del gen $m e c A$, son la resistencia límite a la oxacilina (Borderline Oxacillin-Resistant $S$. aureus, BORSA) en bacterias hiperproductoras de $\beta$-lactamasas, y la resistencia modificada (Modified S. aureus, MODSA) en aquellas que presentan modificaciones en la afinidad de las PBP 1, 3 y 4, por lo que exhiben débil resistencia a la meticilina. Otros genes de resistencia son el gen blaZ y el fem (factor esencial de resistencia a la meticilina) (7).

Asimismo, está la producción de biopelículas, la cual se considera un factor de virulencia. La biopelícula es una comunidad de microorganismos recubiertos de un polímero extracelular o matriz de exopolisacáridos, con la capacidad de adherirse a superficies bióticas o abióticas (10); se ha demostrado que son estructuras tridimensionales (11). La matriz de exopolisacáridos favorece el intercambio de metabolitos con el exterior y confiere una barrera protectora contra ambientes adversos, como la hiperosmolaridad, la anaerobiosis, los anticuerpos, los macrófagos y los antibióticos. Este crecimiento 'protegido' permite la supervivencia en un medio antagonista (11).

La adhesina intercelular de polisacáridos (Polysaccharide Intercellular Adhesin, PIA), llamada poli-N-acetilglucosamina (PNAG), es un polímero de $28 \mathrm{kDa}$, homoglucano lineal de la glucosamina, con una estructura bioquímica de $\beta-1,6-N$-acetil-glucosamina (10). La biosíntesis de la PIA de Staphylococcus spp. participa en la formación de biopelículas $(10,12)$ y se sintetiza por la acción de cuatro proteínas homólogas organizadas en el operón ica, las cuales forman parte del grupo de adhesinas intercelulares (Intercellular Cluster Adhesin, ICA) codificadas por los genes icaA, icaD, icaB e icaC (13). El gen bap puede mediar un mecanismo independiente de la PIA para la formación de la biopelícula $(13,14)$. Por otra parte, la proteína Bap (Biofilm-Associated Protein) se localiza en la superficie bacteriana asociada a la pared celular y desempeña un papel relevante en los procesos infecciosos de la mastitis bovina ocasionada por diferentes especies de Staphylococcus $(13,15)$.

Existe un interés creciente en la formación de biopelículas de bacterias patógenas capaces de adherirse a dispositivos como prótesis ortopédicas, válvulas cardiacas artificiales, marcapasos, injertos de plástico y dispositivos intravenosos temporales o permanentes (11). La tolerancia a los agentes antimicrobianos en el $60 \%$ de las infecciones bacterianas está asociada a la formación de biopelículas y la concentración del agente antimicrobiano requerida para introducirse en la biopelícula y tener efecto en las bacterias (16).

Las cepas de SARM se asocian con infecciones hospitalarias en las que se se pueden formar biopelículas, y se caracterizan por ser persistentes, virulentas y difíciles de eliminar (10). En ese contexto, el objetivo del estudio fue investigar la asociación de la resistencia a la meticilina de los genotipos $m e c A$ e icaADCB con la formación de biopelículas en cepas de $S$. aureus 
y Staphylococcus coagulasa negativa, aisladas de muestras clínicas de pacientes hospitalizados en el Instituto Nacional de Rehabilitación "Luis Guillermo Ibarra Ibarra" de Ciudad de México.

\section{Materiales y métodos}

\section{Cepas bacterianas}

Las cepas utilizadas provenían de muestras clínicas (heridas quirúrgicas, secreciones bronquiales, hemocultivos, puntas de catéter, cultivos óseos) recolectadas durante el periodo de febrero a julio del 2010. Se estudiaron 23 cepas de Staphylococcus spp.: 11 de S. aureus y 12 de Staphylococcus coagulasa negativa. Los aislamientos se obtuvieron por resiembra en placas de gelosa con sangre de carnero y medio agar de sal y manitol. Todas las cepas aisladas fueron positivas para catalasa y negativas para oxidasa. Según la prueba de coagulasa, las cepas se clasificaron como Staphylococcus coagulasa positivas, entre ellas las de $S$. aureus, y Staphylococcus coagulasa negativas. La identificación del género y de la especie se llevó a cabo con un panel bioquímico usando un sistema automatizado (MicroScan Instruments, Dade-Behring). Las cepas se conservaron en caldo de cerebro y corazón con glicerol al $20 \%$ y a $-70{ }^{\circ} \mathrm{C}$ hasta su procesamiento.

Se usó la cepa ATCC 25923 de S. aureus como control negativo para las pruebas de resistencia a la meticilina, la ATCC 43300, como control positivo de la presencia del gen $m e c A$, la ATCC 27543 , como control positivo para la producción de biopelícula, y la ATCC 12228, para la detección de los genes icaA, icaD, icaB e icaC.

\section{Prueba de difusión en disco para oxacilina y cefoxitina}

La sensibilidad a la meticilina se determinó mediante el método de Kirby y Bauer o de difusión mediante el uso de discos de cefoxitina $(30 \mu \mathrm{g})$ (BD BBL Sensi-Disc Antimicrobial ${ }^{\mathrm{TM}}$ ) como método de referencia, según las guías y normas del CLSI (2018) para establecer la sensibilidad a los antimicrobianos mediante discos (17).

Para preparar el inóculo, se seleccionaron cuatro colonias que se colocaron en tubos con $4 \mathrm{ml}$ de caldo Müeller-Hinton; se ajustó la turbidez al 0,5 usando un nefelómetro con el estándar de McFarland (1,5 x 108 UFC/ $\mathrm{ml}$ ); se sembraron con hisopo en tres direcciones en placas de agar MüellerHinton y se colocaron los discos.

Las placas se incubaron durante 24 horas a $37^{\circ} \mathrm{C}$ y se midieron los diámetros de los halos de inhibición en milímetros usando un escalímetro; los resultados se compararon con los valores establecidos en el manual del CLSI (2018) para su clasificación como resistentes o sensibles.

\section{Producción de biopelícula}

La producción de biopelícula se cuantificó con el método de titulación en microplaca de poliestireno utilizando cristal violeta (18). A partir de un cultivo de 24 horas de cada cepa, se preparó una suspensión en caldo de cultivo Müeller-Hinton, y se ajustó a la turbidez del tubo número 3 de McFarland, equivalente a $9,0 \times 10^{8} \mathrm{UFC} / \mathrm{ml}$. Cada ensayo se hizo por cuadruplicado para cada control y para las cepas problemáticas. 
Se agregaron $100 \mu \mathrm{l}$ de esa suspensión a cuatro pozos de microplacas de polipropileno de 96 pozos con fondo plano (Nunc MicroWell ${ }^{\mathrm{TM}}$ ); en los pozos de control negativo se agregó solo el medio Müeller-Hinton y, después, se incubó durante 24 horas a $37^{\circ} \mathrm{C}$. Se aspiró el contenido con micropipetas empleando puntas de $200 \mu$ l estériles y los pozos se lavaron con $100 \mu \mathrm{l}$ de solución tampón fosfato salino (PBS) estéril.

Las bacterias adheridas se fijaron con $100 \mu \mathrm{l}$ de glutaraldehído al 2,5\% durante un minuto a temperatura ambiente, se retiró el exceso aspirando nuevamente y cada uno de los pozos se lavó con $100 \mu \mathrm{l}$ de PBS. Se agregaron $100 \mu \mathrm{L}$ de cristal violeta al $4 \%$ en cada pozo y se incubó a temperatura ambiente durante dos minutos; se retiró el exceso de cristal violeta por aspiración y se lavaron dos veces con PBS. El cristal violeta adherido en cada pozo se disolvió con $100 \mu \mathrm{l}$ de alcohol y acetona en proporción 80:20 (v/v), y el volumen final se ajustó a $2 \mathrm{ml}$ con la misma solución.

Las lecturas se hicieron con un espectrofotómetro a una absorbancia de $570 \mathrm{~nm}$ : se promediaron los valores de las cuatro lecturas de absorbancia, y se calcularon la media y la desviación estándar (DE) para cada una de las cepas y el control negativo. El punto de corte (AbsC) se definió como el valor de tres $D E$ por encima del promedio de las absorbancia del control negativo ( $\mathrm{AbsC}=$ absorbancia media de los controles $+3 X \mathrm{DE}$ de los controles). La absorbancia final de cada una de las cepas se calculó sustrayendo el valor de AbsC (absorbancia=absorbancia de una cepa $-\mathrm{AbsC}$ ).

Cuando el valor obtenido de absorbancia resultó negativo, se consideró como valor cero; cualquier valor positivo indicaba que había producción de biopelícula. La producción de biopelículas se agrupó en cuatro categorías: nula o no adherente (absorbancia $\leq 0,001$ ), baja adherencia (absorbancia $=0,001-0,500$ ), moderada (absorbancia $=0,051-0,900)$ y alta adherencia (absorbancia $\geq 0,901)(19,20)$.

\section{Extracción del ADN genómico}

Para la extracción del ADN genómico, se empleó el método de tiocianato de guanidina: cada cepa se sembró por estría masiva en agar Müeller-Hinton y se incubó a $37^{\circ} \mathrm{C}$ durante 24 horas; las colonias se suspendieron en un $\mathrm{ml}$ de $\mathrm{NaCl}$ al 0,85\%, se centrifugaron a $14,000 \mathrm{~g}$ durante cinco minutos, se lavaron dos veces con $200 \mu \mathrm{l}$ de agar de Salmonella y Shigella y se suspendieron de nuevo en $100 \mu$ de solución tampón tris EDTA (1mM EDTA, $10 \mathrm{mM}$ Tris- $\mathrm{HCl}, \mathrm{pH} 8,0)$.

Se agregaron después $500 \mu \mathrm{l}$ de solución tampón de tiocianato de guanidinio $5 \mathrm{M}$ y EDTA $(0,1 \mathrm{M} \mathrm{pH} 6,0)$, y $25 \mu \mathrm{l}$ de $\mathrm{N}$-Lauril-sarcocinato de sodio al $10 \%$; se mezcló por inversión durante cinco minutos a temperatura ambiente y cinco minutos en hielo. Se agregaron $250 \mu \mathrm{l}$ de acetato de amonio 7,5M y $500 \mu \mathrm{l}$ de cloroformo alcohol isoamílico en proporción 24:1 (v/v); se mezcló por inversión y se centrifugó a $14.000 \mathrm{~g}$ durante siete minutos. Se recuperó la fase acuosa, se agregaron $500 \mu \mathrm{l}$ de isopropanol frío y se dejó a $-20^{\circ} \mathrm{C}$ toda la noche.

EI ADN se recuperó por centrifugación durante 10 minutos a $10.000 \mathrm{~g}$; la pastilla obtenida se lavó con $200 \mu$ l de etanol frío al $70 \%$ (v/v), se centrifugó a $10.000 \mathrm{~g}$ y se dejó secar al aire durante dos horas para, finalmente, disolverla en $80 \mu \mathrm{l}$ de agua para biología molecular. 


\section{Identificación de los genes mecA e icaADBC por reacción en cadena de la polimerasa (PCR)}

Se emplearon los iniciadores específicos diseñados para la amplificación de los genes mecA e icaADBC (21). Las secuencias de los iniciadores específicos, las condiciones de amplificación y los tamaños esperados de cada amplicón se presentan en el cuadro 1.

El volumen final de la mezcla de reacción para la amplificación por PCR fue de $25 \mu \mathrm{l}$; las concentraciones finales de cada uno de los iniciadores fueron de $0,1 \mu \mathrm{M}, 1,5 \mathrm{mM}$ de $\mathrm{MgCl}_{2}, 2,5 \mathrm{mM}$ de dNTP y agua para biología molecular.

Se utilizaron 30 ciclos de desnaturalización inicial durante cinco minutos a $94{ }^{\circ} \mathrm{C}$, desnaturalización durante $30 \mathrm{~s}$ a $94^{\circ} \mathrm{C}$, alineamiento y extensión durante 1,5 minutos a $72{ }^{\circ} \mathrm{C}$ y una extensión final de 10 minutos a $72{ }^{\circ} \mathrm{C}$.

Los productos de la amplificación se visualizaron mediante electroforesis en agarosa al 1,5\% en solución tampón TBE (tris, borato, EDTA) teñido con bromuro de etidio; el tamaño de los amplicones se calculó comparándolos con un marcador de talla molecular comercial de $100 \mathrm{pb}$. El control positivo para la presencia del gen mecA fue el ADN de la cepa ATCC43300 de $S$. aureus.

\section{Análisis estadístico}

El análisis estadístico de la producción de biopelícula se hizo con el programa SPSS ${ }^{\mathrm{TM}}$, versión 20.0. Se hizo un análisis bivariado con las pruebas de ji al cuadrado y el coeficiente $\mathrm{V}$ de Cramér para examinar la asociación entre la resistencia a la meticilina y la formación de biopelícula.

\section{Resultados}

Las 23 cepas de Staphylococcus spp. de origen clínico aisladas se dividieron en dos grupos: el primero con 11 (48 \%) cepas de $S$. aureus, y el segundo con 12 (52\%) cepas de Staphylococcus coagulasa negativa.

El fenotipo resistente a meticilina se encontró en 9 (81,8\%) cepas de $S$. aureus y $2(18,2 \%)$ fueron sensibles. En las cepas del grupo Staphylococcus coagulasa negativa, $8(66,7 \%)$ fueron resistentes y, 4 (33,3\%), sensibles a meticilina (cuadro 2).

Cuadro 1. Secuencias de los iniciadores específicos y condiciones para la amplificación de los genes $m e c A$ e icaADBC

\begin{tabular}{llcr}
\hline Iniciador & Secuencia & $\begin{array}{c}\text { Condiciones de } \\
\text { alineamiento }\end{array}$ & Amplicón (pb) \\
\hline icaA-F & $5^{\prime}$-CGTTGATCAAGATGCACC-3' & $30 \mathrm{~s} / 50^{\circ} \mathrm{C}$ & $319 \mathrm{pb}$ \\
icaA-R & $5^{\prime}$-CCGCTTGCCATGTGTTG-3' & $30 \mathrm{~s} / 50^{\circ} \mathrm{C}$ & \\
icaB-F & $5^{\prime}$-TGGATTAACTTTGATGATATGG-3' & $60 \mathrm{~s} / 54^{\circ} \mathrm{C}$ & $409 \mathrm{pb}$ \\
icaB-R & $5^{\prime}$-AGGAAAAAGCTGTCACACC-3' & $60 \mathrm{~s} / 54^{\circ} \mathrm{C}$ & \\
icaC-F & $5^{\prime}$-GGTCAATGGTATGGCTATTT-3' & $60 \mathrm{~s} / 54^{\circ} \mathrm{C}$ & $148 \mathrm{pb}$ \\
icaC-R & $5^{\prime}$-CGAACAACACAGCGTTTC-3' & $60 \mathrm{~s} / 54^{\circ} \mathrm{C}$ & \\
icaD-F & $5^{\prime}$-GGTCAAGCCCAGACAGAG-3' & $60 \mathrm{~s} / 54^{\circ} \mathrm{C}$ & $150 \mathrm{pb}$ \\
icaD-R & $5^{\prime}$-GAAATTCATGACGAAAGTATC-3' & $60 \mathrm{~s} / 54^{\circ} \mathrm{C}$ & \\
mecA-F & $5^{\prime}$ - TGGCTATCGTGTCACAATCG-3' & $30 \mathrm{~s} / 55^{\circ} \mathrm{C}$ & $310 \mathrm{pb}$ \\
mecA-R & $5^{\prime}$-CTGGAACTTGTTGAGCAGAG-3' & $30 \mathrm{~s} / 55^{\circ} \mathrm{C}$ & \\
\hline
\end{tabular}


Cuadro 2. Fenotipos de sensibilidad y resistencia a la meticilina establecidos por difusión en disco de las cepas de los grupos de Staphylococcus aureus y Staphylococcus aureus coagulasa negativa

\begin{tabular}{lccc}
\hline & \multicolumn{2}{c}{ Fenotipo de sensibilidad a meticilina } & \\
\cline { 2 - 3 } Grupo de cepas & $\begin{array}{c}\text { Sensible a } \\
\text { cefoxitina } \\
\mathbf{n}(\%)\end{array}$ & $\begin{array}{c}\text { Resistente a } \\
\text { cefoxitina } \\
\mathbf{n}(\%)\end{array}$ & $\begin{array}{c}\text { Total } \\
\mathbf{n}(\%)\end{array}$ \\
\hline Staphylococcus aureus & $2(9)$ & $9(39)$ & $11(48)$ \\
Staphylococcus aureus coagulasa negativa & $4(17)$ & $8(35)$ & $12(52)$ \\
Total & $6(26)$ & $17(74)$ & $23(100)$ \\
\hline
\end{tabular}

En cuanto a la correlación entre el fenotipo de resistencia a la meticilina y la presencia del gen $m e c A$, el producto de amplificación mediante PCR de punto final fue el esperado, un amplicón de 310 pares de bases observado por electroforesis en gel de agarosa al 1,5\% (figura 1); de las 23 cepas, 18 (78\%) presentaron este gen.

De las nueve cepas de SARM, ocho presentaron el gen mecA y solo en una no se detectó. En diez cepas de Staphylococcus coagulasa negativa se detectó el gen $m e c A$, es decir, se encontró en las ocho cepas resistentes a la meticilina y, además, en dos cepas con fenotipo sensible a la meticilina y presencia del gen $\operatorname{mec} A(19)$.

En cuanto a la formación de biopelícula como mecanismo de virulencia, se encontró que con las categorías establecidas: nula o no adherente (absorbancia $\leq 0,001$ ), de baja adherencia (absorbancia $=0,001-0,500)$, de moderada adherencia (absorbancia $=0,051-0,900$ ) y de alta adherencia (absorbancia $\geq 0,901$ ), todas las cepas produjeron biopelícula cuando se empleó la cepa ATCC 27543 como control positivo para dicha producción (cuadro 3).

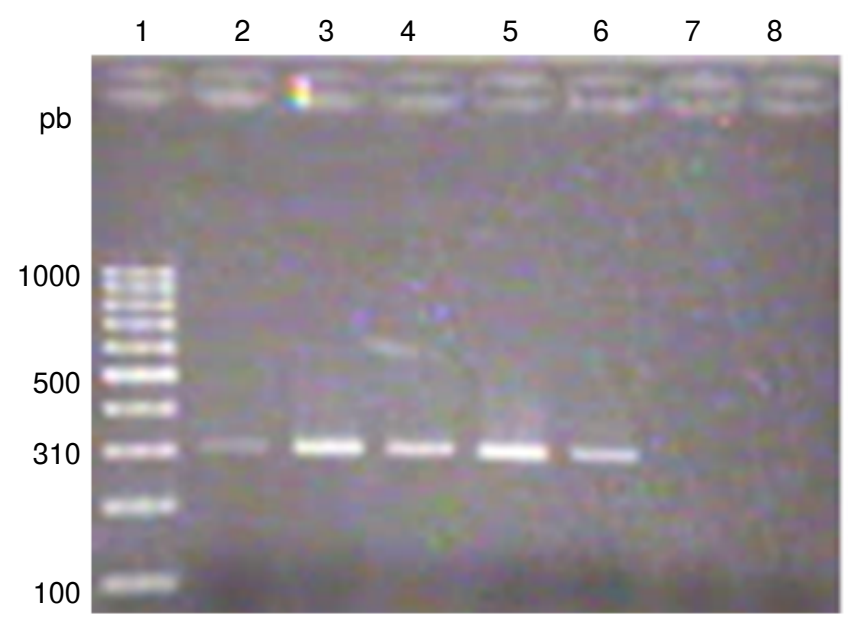

Figura 1. Electroforesis en gel de agarosa al 1,5\% con los amplicones de $310 \mathrm{pb}$ del gen mecA. 1: marcador de talla molecular $100 \mathrm{pb}$; : control positivo con S. aureus ATCC 43300; 3-6: ADN de cepas clínicas de S. aureus; 7: control negativo con S. aureus ATCC 25923; 8: control de reactivos

Cuadro 3. Capacidad de producción de biopelícula en cepas de los grupos de Staphylococcus aureus y Staphylococcus aureus coagulasa negativa

\begin{tabular}{lcccc}
\hline \multirow{2}{*}{ Grupo de cepas } & \multicolumn{3}{c}{ Fenotipo de producción de biopelícula } \\
\cline { 2 - 6 } & $\begin{array}{c}\text { Baja } \\
\mathbf{n}(\%)\end{array}$ & $\begin{array}{c}\text { Moderada } \\
\mathbf{n}(\%)\end{array}$ & $\begin{array}{c}\text { Alta } \\
\mathbf{n}(\%)\end{array}$ & $\begin{array}{c}\text { Total } \\
\mathbf{n}(\%)\end{array}$ \\
\hline Staphylococcus aureus & $3(13)$ & $7(30)$ & $1(5)$ & $11(52)$ \\
Staphylococcus aureus coagulasa negativa & $2(9)$ & $7(30)$ & $3(13)$ & $12(48)$ \\
\hline
\end{tabular}


En el grupo de cepas de Staphylococcus coagulasa negativa se encontraron tres (13\%) con alta producción en comparación con una (5\%) de $S$. aureus. En ambos grupos hubo el mismo número de cepas $(7 ; 30 \%)$ con producción moderada de biopelícula, en tanto que solo tres cepas de $S$. aureus y dos de Staphylococcus coagulasa negativa presentaron el fenotipo de baja producción de biopelícula.

Se amplificaron de manera independiente los genes $A, D, B$ y $C$ del operón ica, con el propósito de correlacionar su presencia con el fenotipo de formación de biopelícula en las cepas de Staphylococcus spp. Las cepas de los dos grupos presentaron el operón icaADBC al usar como control la cepa ATCC 12228 de $S$. epidermidis para la presencia de los genes icaA, icaD, icaB e icaC (figura 2). La electroforesis en geles de agarosa al 1,5\% evidenció en cada cepa los amplicones de cada uno de los genes con el tamaño esperado.

En el análisis estadístico de asociación entre la producción de biopelícula y los dos grupos de cepas de $S$. aureus y Staphylococcus coagulasa negativa mediante el $\mathrm{V}$ de Cramér y la prueba de ji al cuadrado, se encontraron valores de $V$ de 0,245 y de $p$ de 0,111 , lo que indica que las dos variables fueron independientes entre sí. La producción de biopelícula se asoció con las cepas SARM Staphylococcus coagulasa negativa resistente a la meticilina (Methicillin-Resistant Coagulase-Negative Staphylococcus aureus, MRSCN). El análisis estadístico también determinó que la producción de biopelícula se daba independientemente de la resistencia a la meticilina, con un valor de $\mathrm{V}$ de 0,115 y uno de $p$ de 0,252 .
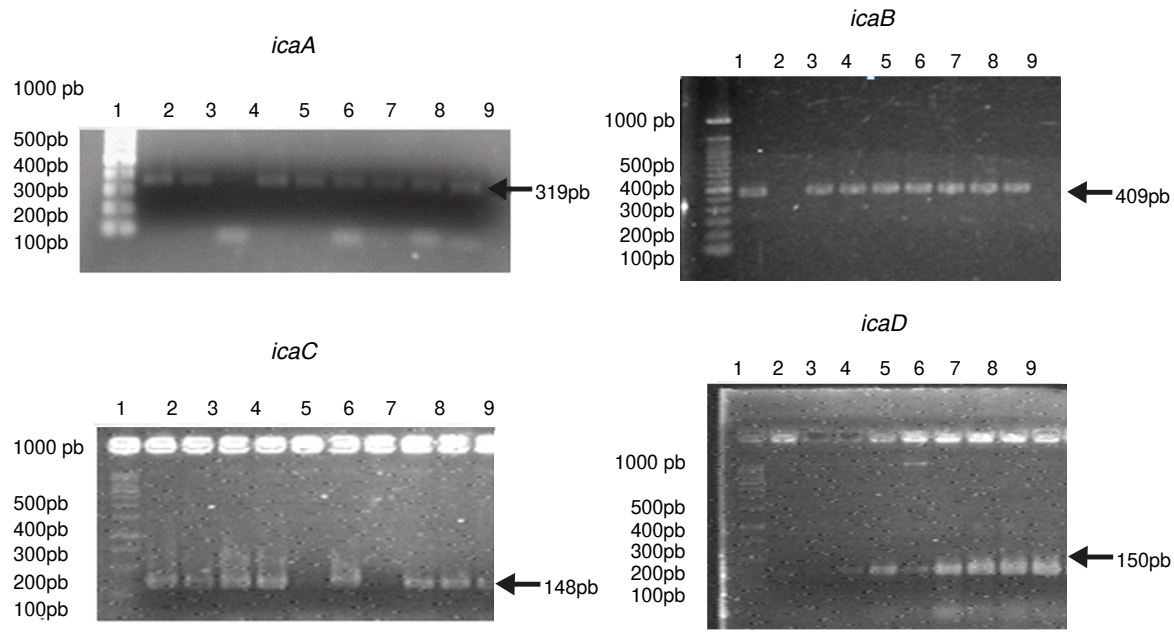

Figura 2. Electroforesis en gel de agarosa al $1,5 \%$ con los amplicones de los genes icaADBC. 1: marcador de talla molecular de 100 pb; 2: control positivo con ATCC 12228; 3-10: cepas clínicas de $S$. aureus.

\section{Discusión}

Las infecciones asociadas con la atención en salud constituyen un grave problema de salud pública en todo el mundo y afectan gravemente a los países de menores recursos. Las infecciones hospitalarias se encuentran entre las principales causas de morbilidad y mortalidad, y su manejo ocasiona costos elevados para los pacientes y el sistema de salud (22).

Staphylococcus aureus y varias especies de Staphylococcus coagulasa negativa, se caracterizan por ser resistentes a la meticilina, lo que, a su 
vez, les confiere resistencia a varios antibióticos $\beta$-lactámicos y dificulta enormemente su erradicación. Por ello, ha sido necesario establecer protocolos específicos de tratamiento con otros antibióticos para las infecciones causadas por este tipo de Staphylococcus spp., con la consiguiente presión selectiva que favorece la diseminación de dichas cepas.

La acumulación y la diseminación de la resistencia en $S$. aureus son producto del intercambio de factores determinantes de resistencia preexistentes en elementos genéticos móviles, como los plásmidos y los transposones (5).

En las muestras de Staphylococcus spp. analizadas en este estudio fue posible determinar el fenotipo resistente a la meticilina utilizando discos con cefoxitina. Las cepas SARM presentaron el mismo rango de sensibilidad y especificidad frente a los dos antibióticos. Estos resultados coinciden con un estudio comparativo de varios métodos de detección de cepas aisladas de muestras clínicas hospitalarias, que presentaron una sensibilidad de $98 \%$ y una especificidad de $100 \%$ utilizando discos de cefoxitina (23).

En las cepas de Staphylococcus coagulasa negativa se detectó el fenotipo de resistencia a la meticilina con los valores de corte de los halos de inhibición. En este sentido, los resultados del presente estudio son similares a los hallados por otros autores (24).

Los métodos de tipificación molecular basados en la detección del gen mecA mediante PCR de punto final están cada vez más al alcance de los laboratorios clínicos y representan una alternativa rápida y eficaz para la detección de cepas SARM. Además, tienen la gran ventaja de no depender de condiciones de cultivo especiales y se pueden usar en un gran número de aislamientos para establecer el fenotipo de resistencia a la meticilina y sus asociaciones.

En el presente estudio encontramos una correlación entre el fenotipo y el genotipo de resistencia a la meticilina; únicamente en una cepa de fenotipo SARM no se encontró el gen mecA.

En cuanto a la formación de biopelícula como factor de virulencia de los estafilococos mediante su adherencia y colonización de células, tejidos y materiales inertes, su determinación in vitro en cepas clínicas ha evolucionado e incluye desde métodos poco reproducibles, como el agar de rojo Congo, hasta los métodos espectrofotométricos semicuantitativos sobre superficies inertes (25).

El método empleado en el presente trabajo presentó una buena reproducibilidad y permitió establecer en los dos grupos tres niveles de formación de biopelícula, predominantemente el moderado.

En diversos estudios se ha demostrado que tanto $S$. aureus como Staphylococcus coagulasa negativa de origen clínico tienen la misma capacidad de formar biopelículas (26). En cepas clínicas de $S$. aureus, resistentes y sensibles a meticilina se ha detectado un nivel moderado de formación de biopelículas, en menor medida, un nivel alto, y en muy pocas cepas, un nivel bajo, sin que se pudiera establecer una correlación entre la resistencia a la meticilina y la capacidad de producción de biopelícula.

Las cepas de $S$. aureus aisladas de la piel de pacientes presentaron una mayor capacidad de producir biopelícula, hecho que favorecería las condiciones para la colonización y la persistencia en el humano si se considera que se trata de uno de los principales microorganismos de la microbiota de la piel (27). 
El operón ica es un elemento importante en la formación y acumulación de biopelícula; consta de cuatro genes que codifican para la adhesina intercelular de polisacárido de las bacterias. En este estudio se encontró que el $91 \%$ de las cepas del grupo de S. aureus y el $92 \%$ de las del grupo de Staphylococcus coagulasa negativa presentaron los genes icaADBC. La capacidad de formar biopelícula depende, en parte, de la actividad del locus icaADBC y del gen icaR implicados en la producción de la adhesina intercelular de polisacárido la cual es necesaria funcionalmente para la adherencia entre células y para la acumulación de biopelícula. Estos resultados coinciden con los de otro estudio (14), en el que se obtuvo una alta frecuencia de genes icaADBC en todos los aislamientos clínicos.

Aunque esta adhesina es un factor muy importante en la formación de biopelícula, se identificaron cepas que no codificaron para los genes icaADBC y, por lo tanto, no sintetizan el polisacárido. Este resultado no implica que no tengan la capacidad de formar biopelícula, sino que otros genes no incluidos en el estudio citado, como el SigB, el SarA y el LuxS, que también participan en la producción de biopelícula, podrían estar implicados (14).

La resistencia a la meticilina y la producción de biopelícula en los aislamientos clínicos de $S$. aureus y Staphylococcus coagulasa negativa son factores de virulencia que se expresan de manera independiente. Se obtuvo una importante correlación entre el fenotipo resistente a la meticilina y el genotipo del $\operatorname{mec} A$ en las cepas de origen clínico. Prácticamente todas las cepas fueron capaces de formar biopelícula, ya fuera por la participación del operón ica o por la de otros genes que no fueron parte de esta investigación.

Los estudios biotecnológicos fenotípicos y biomoleculares mediante PCR en infecciones hospitalarias han contribuido a un mejor conocimiento de su persistencia y resistencia antimicrobiana, y favorecen un mejor manejo clínico y terapéutico. La metodología empleada permitió aislar y clasificar las 23 cepas de Staphylococcus spp. procedentes de diferentes casos clínicos en dos grupos: $S$. aureus y Staphylococcus coagulasa negativa. Se pudo determinar mediante PCR que 18 de las 23 cepas presentaron el gen mecA, pero en una cepa con fenotipo de resistencia no se lo detectó, lo que sugiere un mecanismo de resistencia alterno. No se demostró asociación entre la producción de biopelícula y la resistencia a la meticilina.

\section{Referencias}

1. Guzmán-Blanco M, Mejía C, Isturiz R, Álvarez C, Bavestrello L, Gotuzzo E, et al. Epidemiology of meticillin resistant Staphylococcus aureus (MRSA) in Latin America. Int J Antimicrob Agents. 2009;34:304-8. https://doi.org/10.1016/j.ijantimicag.2009.06.005

2. Red Hospitalaria de Vigilancia Epidemiológica. Informe anual 2015. México: Secretaría de Salud; 2015.

3. Bannerman TL, Peacock SJ. Staphylococcus, Micrococcus, and other catalase-positive cocci. En: Murray PR, Baron EJ, Jorgensen JH, Landry ML, Pfaller MA, editors. Manual of clinical microbiology. 9th edition. Washington, D.C.: ASM Press; 2007. p. 390-411.

4. Bustos-Martínez JA, Hamdan-Partida A, Gutiérrez-Cárdenas. Staphylococcus aureus: la reemergencia de un patógeno en la comunidad. Rev Biomed. 2006;17:287-305.

5. Velázquez-Meza ME. Surgimiento y diseminación de Staphylococcus aureus meticilino resistente. Salud Pública de México. 2005;47:381-7.

6. Marín M, Gudiol F. Antibióticos beta-lactámicos. Enferm Infecc Microbiol Clin. 2003;21:4255. https://doi.org/10.1016/S0213-005X(03)72873-0

7. Chambers HF, Deleo FR. Waves of resistance: Staphylococcus aureus in the antibiotic era. Nat Rev Microbiol. 2009;7:629-41. https://doi.org/10.1038/nrmicro2200 
8. Zhang HZ, Hackbart CJ, Chansky KM, Chambers HF. A proteolytic transmembrane pathway and resistance to $\beta$ lactams in staphylococci. Science. 2001;291:1962-5.

https://doi.org/10.1126/science.1055144

9. Hiramatsu K. Vancomycin resistant Staphylococcus aureus: A new model of antibiotic resistance. Lancet Infec Dis. 2001;1:147-55 https://doi.org/10.1016/S1473-3099(01)00091-3

10. Hernández JB, Novales GM. Biofilm. ¿Amenaza latente o factor de protección? Estado de arte. Enferm Infecc Microbiol Clin. 2007;27:22-8.

11. Hall-Stoodley L, Costerton JW, Stoodley P. Bacterial biofilms: From the natural environment to infectious diseases. Nat Rev Microbiol. 2004;2:95-108. https://doi.org/10.1038/nrmicro821

12. Otto M. Staphylococcus epidermidis the "accidental" pathogen. Nat Rev Microbiol. 2009;7:555-67. https://doi.org/10.1038/nrmicro2182

13. Lasa I. Towards the identification of the common features of bacterial biofilm development. Int Microbiol. 2006;9:21-8.

14. O'Gara PJ. ica and beyond: Biofilms mechanism and regulation in Staphylococcus epidermidis and Staphylococcus aureus. FEMS Microbiol Lett. 2007;270:179-88. https://doi.org/10.1111/j.1574-6968.2007.00688.x

15. Cucarella C, Tormo MA, Knecht E, Amorena B, Lasa I, Foster TJ, et al. Expression of the biofilm associate protein interferes with host protein receptors of Staphylococcus aureus and alters the infective process. Infect Immun. 2002;70:3180-8. https://doi.org/10.1128/IAl.70.6.3180-3186.2002

16. Rodríguez-Martínez JM, Pascual Á. Actividad de los antimicrobianos en biocapas bacterianas. Enferm Infecc Microbiol Clin. 2008;26:107-14. https://doi.org/10.1157/13115546

17. Clinical and Laboratory Standards Institute. Antimicrobial susceptibility testing standards. M02-A11, M07-A9, and M11-A8. Wayne: ILSI; 2014.

18. Stepanovic S, Vukovic D, Dakic I, Savic B, Svabic-Vlahovic M. A modified microtiter-plate test for quantification of staphylococcal biofilm formation. J Microbiol Methods. 2000;40:1759. https://doi.org/10.1016/S0167-7012(00)00122-6

19. García-Barreto AA. Biofilm de Staphylococcus spp. de origen intrahospitalario: genes asociados (tesis). México: Instituto Politécnico Nacional; 2010.

20. Acosta-Pérez G, Rodríguez-Ábrego G, Longoria-Revilla E, Castro-Mussot ME. Evaluación de cuatro métodos para la detección de Staphylococcus aureus meticilino-resistente de muestras clínicas en un hospital regional. Salud Pública de México. 2012;54:1-6.

21. Gómez J, Gómez-Lus ML, Bas P, Ramos C, Cafini F, Maestre JR, et al. ¿Es la cuantificación del biofilm un elemento diferenciador en la patogenia de bacilos gramnegativos? Rev Esp Quimioter. 2013;26:97-102.

22. Ducel G, Fabry J, Nicolle L. Prevención de las infecciones nosocomiales. Guía práctica. Segunda edición. México: Organización Mundial de la Salud; 2003. p. 1-65.

23. Zayas-Tamayo ÁM, Barreras-García G, Álvarez-Varela E. Detección mediante el Sistema DIRAMIC de Staphylococcus aureus resistente a meticilina (SARM) y comparación con otros métodos utilizado en la práctica clínica. Revista CENIC Ciencias Biológicas. 2013;44. Fecha de consulta: 23 de noviembre de 2017. Disponible en: https://revista.cnic.edu.cu/revistaCB/ sites/default/files/articulos/CB28-12.pdf

24. Corso A, Soloaga R, Faccone D, Gagetti P, Corbella S, Iglesias M, et al. Improvement of a latex agglutination test for the evaluation of oxacillin resistance in coagulase-negative staphylococci. Diagn Microbiol Infect Dis. 2004;50:223-5. https://doi.org/10.1016/j.diagmicrobio.2004.06.005

25. Peeters E, Nelis HJ, Coenye T. Comparison of multiplex methods for quantification of microbial biofilms grown in microtiter plates. J Microbiol Methods. 2007;11:9-18. https://doi.org/10.1016/j.mimet.2007.11.010

26. Arslan S, Ozkardes F. Slime production and antibiotic susceptibility in Staphylococci isolated from clinical samples. Mem Inst Oswaldo Cruz. 2007;102:29-33. https://doi.org/10.1590/S0074-02762007000100004

27. Smith K, Pérez A, Ramage G, Lappin D, Gemmell CG, Lang S. Biofilm formation by Scottish clinical isolates of Staphylococcus aureus. J Med Microb. 2008;57:1018-23.

https://doi.org/10.1099/jmm.0.2008/000968-0 